\title{
PENGARUH PROMOSI PENJUALAN DAN PERSONAL SELLING TERHADAP KEPUTUSAN PENGAMBILAN KREDIT PADA NASABAH BANK CIMB NIAGA CABANG ASIA AFRIKA BANDUNG
}

\author{
Vivin Rahmawati ${ }^{1}$, Tahmat $^{2}$ \\ ${ }^{1,2}$ Program Studi S1 Manajemen Fakultas Ekonomi, Universitas Sangga buana YPKP \\ ${ }^{1}$ korespondensi : vivinrahmawati03@gmail.com
}

\begin{abstract}
In an effort to increase credit realization, Bank CIMB Niaga uses promotions. Promotional activities carried out are sales promotion and personal selling. Sales promotion has advantages in terms of promotion of banking products because sales promotion can create new customers through exhibitions, while personal selling has advantages up to the negotiation stage considering that direct communication can be carried out so that it will affect the level of credit making decisions, but seen from the data on bank credit realization, it has decreased. This study aims to determine how much influence the variables of Sales Promotion and Personal Selling partially or simultaneously on Credit Making Decisions on Customers of Bank CIMB Niaga Asia Afrika Bandung Branch. The sample used in this study with a total of 92 respondents. The method used in this research is descriptive analysis and verification. Descriptive method to describe and describe the variables of sales promotion and personal selling on credit decisions. Verification method to determine the relationship between sales promotion and personal selling on credit decisions. The analysis technique uses multiple linear regression analysis.
\end{abstract}

Keywords: Sales Promotion, Personal Selling, Credit Decisions

\begin{abstract}
ABSTRAK
Dalam upaya meningkatkan realisasi kredit Bank CIMB Niaga menggunakan promosi. Kegiatan promosi yang dilakukan adalah promosi penjualan dan personal selling. Promosi penjualan memiliki kelebihan dalam hal promosi produk perbankan karena promosi penjualan dapat menciptakan nasabah baru melalui pameran sedangkan personal selling memiliki kelebihan sampai tahap negosiasi mengingat dapat dilakukan komunikasi langsung sehingga akan mempengaruhi tingkat keputusan pengambilan kredit, namun dilihat dari data realisasi kredit bank mengalami penurunan. Penelitian ini bertujuan untuk mengetahui seberapa besar pengaruh variabel Promosi Penjualan dan Personal Selling secara parsial maupun simultan terhadap Keputusan Pengambilan Kredit Pada Nasabah Bank CIMB Niaga Cabang Asia Afrika Bandung. Sampel yang digunakan dalam penelitian ini dengan jumlah 92 responden. Metode yang digunakan dalam penelitian ini adalah analisis deskriptif dan verifikatif. Metode deskriptif untuk mendeskripsikan dan menggambarkan variabel promosi penjualan dan personal selling terhadap keputusan pengambilan kredit. Metode verifikatif untuk mengetahui hubungan antar promosi penjualan dan personal selling terhadap keputusan pengambilan kredit. Teknik analisanya menggunakan analisis regresi linier berganda Berdasarkan hasil penelitian secara keseluruhan baik parsial maupun simultan variabel Promosi Penjualan dan Personal Selling berpengaruh postif dan signifikan terhadap variabel Keputusan Pengambilan Kredit.
\end{abstract}

Kata Kunci: Promosi Penjualan, Personal Selling, Keputusan Pengambilan Kredit.

\section{PENDAHULUAN}

Saat ini persaingan dalam industri perbankan sangat ketat dikarenakan meningkatnya jumlah Bank dari tahun ke tahun. Hal tersebut membuat bank mencari cara untuk meningkatkan realisasi kredit sesuai target yang telah ditentukan, namun bank mengalami permasalahan berkaitan dengan meningkatkan keputusan pengambilan kredit tanpa agunan yang menimbulkan penurunan realisasi kredit 
(tidak sesuai dengan target yang telah di tetapkan).

Promosi memiliki peranan yang sangat penting. Kegiatan promosi yang dilakukan adalah promosi penjualan dan personal selling. Promosi penjualan memiliki kelebihan dalam hal promosi produk perbankan, hal ini disebabkan karena promosi penjualan dapat menciptakan nasabah baru melalui pameran dan event sedangkan personal selling memiliki kelebihan sampai tahap negosiasi mengingat dapat dilakukan komunikasi langsung (tatap muka).

Promosi penjualan yang dilakukan ditempat event atau pameran dilakukan dengan cara membagikan brosur kepada nasabah yang melewati lokasi event atau booth dan Personal Seling dilakukan dengan cara komunikasi langsung dengan menawarkan produk kredit kepada nasabah, mempersentasikan produk kredit, menyampaikan keunggulan dan manfaat kredit serta tanya jawab dengan nasabah sehingga mempengaruhi nasabah dalam mengambil keputusan pengambilan kredit.

Berikut ini adalah data realisasi kredit dalam kegiatan event Bank CIMB Niaga Cabang Asia Afrika Bandung periode bulan Januari sampai dengan bulan Juni 2020 :

Table 1 : Data Realisasi Kredit dalam Kegiatan Event dari bulan Januari - Juni 2020

\begin{tabular}{|c|c|c|}
\hline Bulan & Jumlah Nasabah & Realisasi Kredit \\
\hline Januari & 487 Nasabah & Rp 2.984.000.000 \\
\hline Februai & 469 Nasabah & Rp 2.873 .000 .000 \\
\hline Maret & 322 Nasabah & Rp 1.926 .000 .000 \\
\hline April & 282 Nasabah & Rp 1.657 .000 .000 \\
\hline Mei & 137 Nasabah & Rp 890.000 .000 \\
\hline Juni & 109 Nasabah & Rp 800.000.000 \\
\hline
\end{tabular}

Berdasarkan tabel 1 dapat di jelaskan bahwa realisasi kredit mengalami penurunan dari bulan ke bulan berikutnya. Adanya penurunanrealisasi kredit tanpa agunan di duga penyebabnya karena persaingan bunga kredit, kondisi ekonomi menurun, proses kredit, pelayanannya (SDM dan teknologi), dan efektifitas kegiatan personal selling dan promosi penjualan. Oleh karena itu menarik untuk menjadikan Kredit Bank CIMB Niaga sebagai objek penelitian.

Berdasarkan latar belakang yang telah diuraikan sebelumnya maka dapat dirumuskan masalah sebagai berikut:

1. Bagaimana Promosi Penjualan di Bank CIMB Niaga Cabang Asia Afrika.

2. Bagaimana Personal Selling di Bank CIMB Niaga Cabang Asia Afrika.

3. Bagaimana Keputusan Pengambilan Kredit di Bank CIMB Niaga Cabang Asia Afrika.

4. Sejauh mana pengaruh Promosi Penjualan dan Personal Selling terhadap Keputasan Pengambilan Kredit baik secara parsial maupun simultan pada nasabah Bank CIMB Niaga Cabang Asia Afrika. 
Tujuan dari penelitian yang peneliti lakukan adalah:

1. Untuk mengetahui pengaruh PromosiPenjualan di Bank CIMB Niaga Cabang Asia Afrika.

2. Untuk mengetahui pengaruh Personal Selling di Bank CIMB Niaga Cabang Asia Afrika.

3. Untuk mengetahui Keputusan Pengambilan Kredit di Bank CIMB Niaga Cabang Asia Afrika.

4. Untuk mengetahui sejauh mana pengaruh Promosi Penjualan dan Personal Selling terhadap Keputusan Pengambilan Kredit baik secara parsial maupun simultan pada Nasabah Bank CIMB Niaga Cabang Asia Afrika..

\section{TINJAUAN PUSTAKA}

\section{Promosi Penjualan}

"Promosi penjualan adalah bentuk persuasi langsung melalui penggunaan berbagai insentif yang dapat diatur untuk merangsang pembelian produk dengan segera dan/atau meningkatkan jumlah barang yang dibeli pelanggan"[1].

Dimensi-dimensi dari promosi penjualan [2] terdiri dari:

1. Alat Promosi Konsumen, mencakup contoh produk (sample), kupon, pengembalian uang tunai, kumpulan harga, bingkisan premium, pemasangan iklan khusus, penghargaan pelanggan, pameran dan demonstrasi di titik pembelian, serta kontes, undian berhadiah, dan permainan.

2. Alat Promosi Perdagangan, terdiri dari diskon langsung atas daftar harga setiap bungkus yang dibeli selama satu periode tertentu, penawaran tunjangan berupa potongan yang besar per bungkus sebagai imbalan atas kesepakatan pengecer karena menampilkan produk pabrikan dalam cara tertentu, serta penawaran barang gratis yang merupakan bungkusan barang dagangan tambahan kepada perantara perdagangan yang membeli dalam jumlah tertentu.

3. Alat Promosi Bisnis, yang digunakan untuk menghasilkan pelopor bisnis,dan memotivasi tenaga penjualan

\section{Personal Selling}

Penjualan pribadi adalah komunikasi langsung antara penjual dan calon pembeli untuk memperkenalkan suatu produk kepada calon pembeli dan membentuk pemahaman pelanggan terhadap suatu produk mereka kemudian akan mencoba membelinya [3].

Personal selling memiliki 6 dimensi utama [4] yang sangat penting yaitu mencari dan memilih prospek, pendekatan pendahuluan, presentasi dan demonstrasi, menangani penolakan, menutup transaksi penjualan, menindak lanjuti.

\section{Keputusan Pengambilan Kredit}

Keputusan pengambilan kredit merupakan sebuah proses keputusan dalam mengambil kredit pada suatu lembaga keuangan yang dimulai dari pengenalan masalah, pencarian 
informasi, penilaian alternatif, membuat keputusan, dan akhirnydidapatkan perilaku setelah mengambil kredit yaitu puas atau tidak puas atas suatu produk tersebut [5].

\section{Dimensi dan Indikator Keputusan}

\section{Pengambilan Kredit}

Indikator keputusan pengambilan kredit oleh nasabah yaitu persepsi melihat kinerja performace karyawan, kepuasan akan kredit yang ditawarkan, penyediaan informasi pada saat diminta, kepercayaan terhadap kelompok referensi, pertimbangan pelayanan [5].

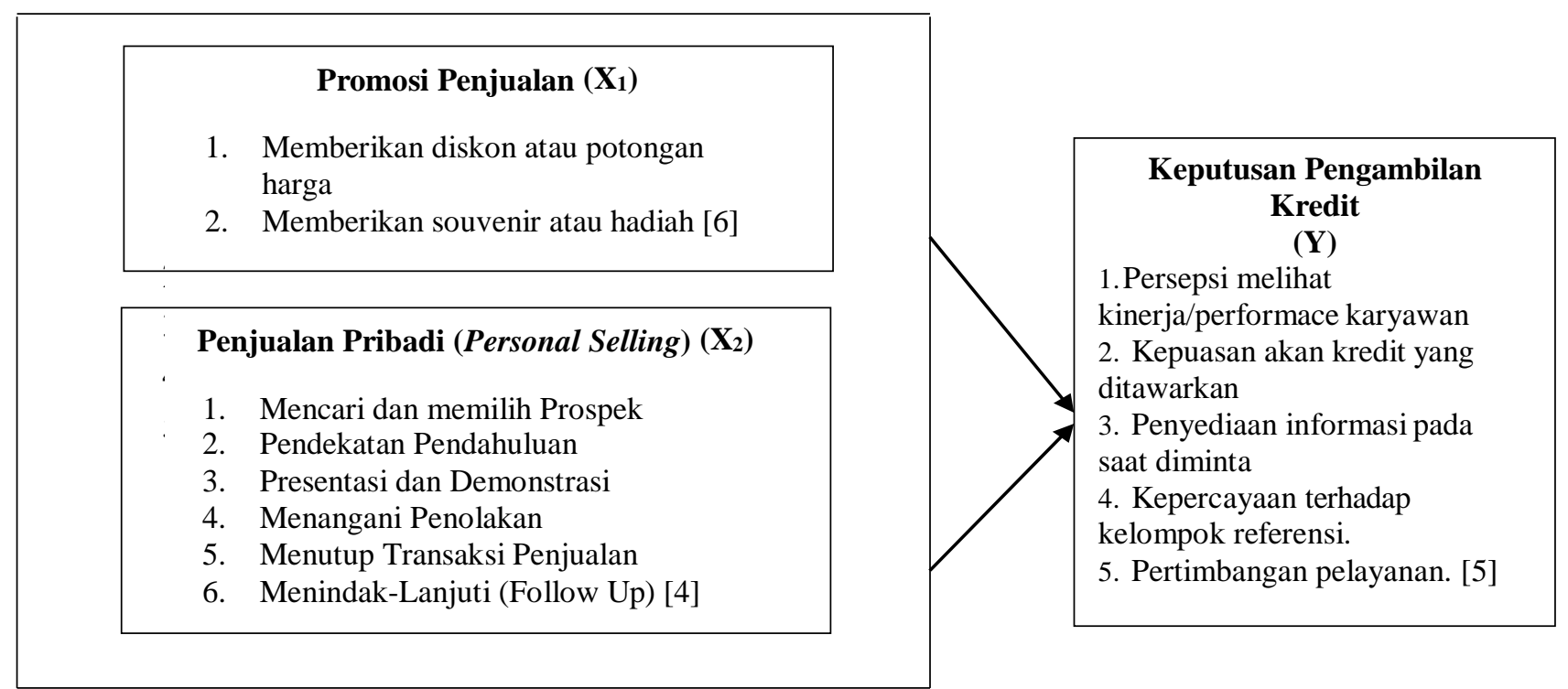

Gambar 1 : Paradigma Penelitian

\section{Pengaruh Promosi Penjualan Terhadap Keputusan Pengambilan Kredit}

Promosi penjualan merupakan insentif jangka pendek untuk mendorong penjualan. Oleh karena itu promosi penjualan merupakan sarana untuk mendorong konsumen agar melakukan keputusan pengambilan kredit. Hal ini juga didukung dengan penelitian sebelumnya yang hasilnya menunjukan bahwa promosi penjualan berpengaruh positif dan signifikan terhadap minat nasabah bertransaksi di bank syariah.
Sehingga semakin kuat Promosi Penjualan yang dimiliki oleh perusahaan maka akan semakin meningkatkan minat nasabah bertransaksi di bank syariah.

\section{Pengaruh Personal Selling terhadap}

\section{Keputusan Pengambilan Kredit}

Personal Selling merupakan sarana untuk mempermudah konsumen dalam mengenal suatu produk atau jasa yang akan menarik menarik minat konsumen untuk melakukan keputusan pengambilan kredit. Hal ini 
ISBN 978-623-92199-2-5

didukung oleh penelitian sebelumnya hasilnya menunjukan bahwa Personal Selling berpengaruh positif dan signifikan terhadap keputusan nasabah dalam memilih pembiayaan mikro [7]. Sehingga semakin kuat Personal Selling yang dimiliki oleh perusahaan maka akan semakin meningkatkan keputusan nasabah dalam memilih pembiayaan mikro.

\section{Pengaruh Promosi Penjualan dan Personal} Selling terhadap Keputusan Pengambilan

\section{Kredit}

Promosi penjualan dan personal selling berhubungan dengan Keputusan Pengambilan Kredit, semakin kuat promosi penjualan pada mengenalkan suatu produk yang semula konsumen tidak tertarik terhadap suatu produk bisa berubah fikiran dan menjadi tertarik pada produk tersebut maka akan semakin kuat juga ketertarikan

konsumen dalam pengambilan produk dan jika personal selling yang dilakukan sesuai dengan yang dibutuhkan oleh konsumen. Hal ini didukung oleh penelitian sebelumnya, hasilnya menunjukan bahwa Promosi Penjualan dan Personal Selling berpengaruh positif terhadap keputusan nasabah menabung [8]. Sehingga semakin kuat Promosi Penjualan dan Personal Selling yang dimiliki oleh perusahaan maka akan semakin meningkatkan keputusan nasabah menabung.

Berdasarkan paradigma penelitian, maka hipotesis yang diajukan dalam penelitian ini adalah Pengaruh Promosi Penjualan Dan
Personal Selling Terhadap Keputusan Pengambilan Kredit Pada Nasabah Bank CIMB Niaga Cabang Asia Afrika Bandung.

\section{METODE PENELITIAN}

Penelitian ini dilakukan di Bank CIMB Niaga Cabang Asia Afrika Bandung. Populasi pada penelitian ini adalah nasabah Bank CIMB Niaga. Teknik pengambilan sample menggunakan teknik slovin, dimana sample yang didapat berjumlah 92 orang. Untuk membantu peneliti mendapatkan jawaban dari responden digunakan alat bantu kuesioner yang berisi pernyataan tertutup denganserangkaian alternative pilihan jawaban yang terdapat didalam kuesioner. Alternative jawaban yang terdapat dalam kuesioner merupakan pengembangan dari setiap item dari variabel penelitian. Dalam penelitian ini indicator diukur dengan menggunakan skala likert. Peneliti melakukan pengujian uji validitas dan reabilitas.

Selanjutnya dari data yang valid dilakukan teknik analisis data deskriptif unttuk menggambarkan sustu keadaan dan penelitian verifikatif untuk mengetahui hubungan antar variabel independen dan dependen. Analisis regresi linier berganda dalam penelitian ini bertujuan untuk mengetahui seberapa besar pengaruh variabel independen (Promosi Penjualan dan Personal Selling) terhadap variabel dependen (Keputusan Pengambilan Kredit) dengan menggunakan rumus :

$\mathrm{Y}=\alpha+\beta_{1} \mathrm{X}_{1}+\beta_{2} \mathrm{X}_{2}+\epsilon$ 
Keterangan:

Y : Keputusan Pengambilan Kredit

$\mathrm{X}_{1}$ : Promosi Penjualan

b : Koefisien Regresi

a : konstanta

$\mathrm{X}_{2}$ : Personal Selling

$\epsilon$ : epsilon

Selanjutnya dalam melakukan hipotesis di lakukan 2 pengujian yaitu Uji simultan (Uji

F) dan Uji parsial (Ujit).

\section{HASIL DAN PEMBAHASAN}

\section{Gambaran Responden}

Hasil yang diperoleh dari responden, berdasarkan jenis kelamin di Bank CIMB Niaga Cabang Asia Afrika Bandung didominasi oleh perempuan sebanyak 53,3\%. Berdasarkan usia didominasi oleh usia 21-30 tahun sebanyak $53,3 \%$. Berdasarkan jenis pekerjaan didominasi oleh karyawan swasta sebanyak 48,9\%. Sedangkan berdasarkan penghasilan perbulan didominasi oleh penghasilan $\mathrm{Rp}$
3.000 .000 - Rp 5.000.000 perbulan sebanyak $35,8 \%$.

\section{Uji Validitas}

Uji validitas digunakan untuk mengukur valid atau tidaknya setiap item dalam kuesioner pada penelitian. Dinyatakan valid apabila item kuesioner memiliki nilai $\mathrm{r}$ hitung lebih besar dari rtabel.Dalam penelitian ini memiliki 24 pertanyaan, semua item pertanyaan valid karena semua item pertanyaan memiliki nilai rhitung > rtabel $(0,172)$.

\section{Uji Reabilitas}

Uji reabilitas digunakan untuk melihat konsistensi hasil pengukuran. Hasil

\section{Uji Normalitas}

perhitungan uji relibilitas pada penelitian ini memiliki nilai Cronback Alpha diatas 0,6 maka hasilnya dikatakan reliabel sehingga instrument atau angket ini termasuk kepada instrument reliabel dan konsisten.

Tabel 2 : Hasil Uji Normalitas

\begin{tabular}{|c|c|c|}
\hline \multicolumn{3}{|c|}{ One-Sample Kolmogorov-Smirnov Test } \\
\hline & & Unstandardized Residual \\
\hline \multicolumn{2}{|l|}{$\mathrm{N}$} & 92 \\
\hline \multirow[t]{2}{*}{ Normal Parameters ${ }^{\mathrm{a}, \mathrm{b}}$} & Mean & .0000000 \\
\hline & Std. Deviation & 3.49495702 \\
\hline \multirow{3}{*}{$\begin{array}{l}\text { Most Extreme } \\
\text { Differences }\end{array}$} & Absolute & .075 \\
\hline & Positive & .075 \\
\hline & Negative & -.059 \\
\hline \multicolumn{2}{|l|}{ Test Statistic } & .075 \\
\hline \multicolumn{2}{|l|}{ Asymp. Sig. (2-tailed) } & $.200^{\mathrm{c}, \mathrm{d}}$ \\
\hline \multicolumn{3}{|c|}{ a. Test distribution is Normal. } \\
\hline \multicolumn{3}{|l|}{ b. Calculated from data. } \\
\hline \multicolumn{3}{|c|}{ c. Lilliefors Significance Correction. } \\
\hline \multicolumn{3}{|c|}{ d. This is a lower bound of the true significance. } \\
\hline
\end{tabular}

Sumber : Hasil Pengolahan SPSS 24 
Dilihat dari data di atas diperoleh 0,200 >,05

maka distribusi data pengujian ini dinyatakan normal.

Tabel 3 : Hasil Uji Multikolinearitas

\begin{tabular}{|l|l|l|l|}
\hline \multirow{2}{*}{ Model } & \multicolumn{2}{|l|}{ Collinearity Statistics } \\
\cline { 3 - 4 } 1 & Tolerance & VIF \\
\hline \multirow{3}{*}{\begin{tabular}{l} 
(Constant) \\
\multicolumn{2}{|l|}{ a. Dependent Variable: KEPUTUSAN PENGAMBILAN KREDIT }
\end{tabular}} \\
\cline { 2 - 4 } & PROMOSI PENJUALAN & 840 & 1.190 \\
\hline
\end{tabular}

Sumber : Hasil Pengolahan SPSS 24

Dari hasil uji pada tabel 3 nilai toleransi untuk

Promosi Penjualan (X1) dan Personal Selling (X2) bernilai 0,840 yang nilainya lebih besar dari 0,1 dan VIF bernilai 1,190 yang nilainya tidak lebih dari 10. Maka dapat disimpulkan bahwa tidak terjadi kolerasi anta variable independen dikatakan model regresi yang baik.

Tabel 4 : Hasil Uji Heteroskedastisitas

\begin{tabular}{|c|c|c|c|}
\hline \multicolumn{4}{|c|}{ Coefficients $^{\mathrm{a}}$} \\
\hline \multicolumn{2}{|r|}{ Model } & $\mathrm{T}$ & Sig. \\
\hline \multirow[t]{3}{*}{1} & (Constant) & 3.542 & .001 \\
\hline & PROMOSI PENJUALAN & -1.877 & .064 \\
\hline & PERSONAL SELLING & .102 & .919 \\
\hline \multicolumn{4}{|c|}{ a. Dependent $V_{c}$} \\
\hline
\end{tabular}

Dari hasil uji pada tabel 4.38 nilai signifikansi maka dapat disimpulkan bahwa terjadi korelasi (sig) untuk Promosi Penjualan (X1) dan antar variabel independen dikatakan model Personal Selling (X2) bernilai lebih dari 0,05 regresi yang baik.

Tabel 5 : Hasil Analisis Regresi Linier Berganda

\begin{tabular}{|c|c|c|c|c|c|c|}
\hline \multicolumn{7}{|c|}{ Coefficients $^{\mathrm{a}}$} \\
\hline \multirow{2}{*}{\multicolumn{2}{|c|}{ Model }} & \multicolumn{2}{|c|}{ Unstandardized Coefficients } & \multirow{2}{*}{\begin{tabular}{|l} 
Standardized Coefficients \\
Beta
\end{tabular}} & \multirow[b]{2}{*}{$\mathrm{t}$} & \multirow[b]{2}{*}{ Sig. } \\
\hline & & B & Std. Error & & & \\
\hline 1 & (Constant) & 4.259 & 1.991 & & 2.139 & .035 \\
\hline & PROMOSI PENJUALAN & .767 & .139 & .382 & 5.527 & .000 \\
\hline & PERSONAL SELLING & .339 & .041 & .568 & 8.218 & .000 \\
\hline
\end{tabular}

a. Dependent Variable: KEPUTUSAN PENGAMBILAN KREDIT

b. Linier Regression through the origin

Sumber : Hasil Pengolahan SPSS 24

Berdasarkan hasil perhitungan pada tabel 5 diperoleh persamaan regresi linier berganda dengan model regresi linier origin atau model regresi tanpa konstanta, sehingga diperoleh 
persamaan berikut :

$\mathrm{Y}=4,295+0,767 \mathrm{X} 1+0,339 \mathrm{X} 2+\epsilon$

Keterangan :

$\mathrm{Y}=$ Keputusan Pengambilan Kredit

$\mathrm{X} 1=$ Promosi Penjualan

$\mathrm{X} 2 \quad=$ Personal Selling

$B \quad=$ Koefisien Regresi

$$
\begin{array}{ll}
\epsilon & =\text { Epsilon } \\
\alpha & =\text { Konstanta }
\end{array}
$$

Berdasarkan analisis tersebut, dapat dijelaskan adanya pengaruh atau keeratan hubungan antara variabel Promosi penjualan dan Personal Selling terhadap variable Keputusan Pengambilan Kredit )

Tabel 6 : Hasil Uji Koefisien Determinasi

\begin{tabular}{|c|c|c|c|c|}
\hline \multicolumn{5}{|c|}{ Model Summary $^{\mathbf{b}}$} \\
\hline Model & $\mathrm{R}$ & $\mathrm{R}$ Square & $\begin{array}{c}\text { Adjusted R } \\
\text { Square }\end{array}$ & $\begin{array}{c}\text { Std. Error of the } \\
\text { Estimate }\end{array}$ \\
\hline 1 & $.802^{\mathrm{a}}$ & .643 & .635 & 3.53401 \\
\hline
\end{tabular}

Sumber : Hasil Pengolahan SPSS 24

Hasil analisis data 6 terlihat besarnya angka koefisien determinasi ( $\mathrm{R}$ square) yaitu sebesar 0,643 atau sama dengan $64,3 \%$. Nilai tersebut mengandung arti bahwa variabel promosi penjualan (X1) dan personal selling (X2) secara simultan (Bersama -sama) berpengaruh terhadap variabel keputuan pengambilan kredit (Y) sebesar $64,3 \%$ sedangkan sisanya (100\% $64,3 \%=35,7 \%)$

sisanya $35,7 \%$ dipengaruhi oleh variabel lain diluar persamaan regresi ini atau variabel yangtidak diteliti.

\section{Uji Hipotesis}

\begin{tabular}{|c|c|c|c|c|c|c|}
\hline \multicolumn{7}{|c|}{ ANOVA $^{\mathrm{a}}$} \\
\hline \multicolumn{2}{|c|}{ Model } & Sum of Squares & Df & Mean Square & F & Sig. \\
\hline \multirow[t]{3}{*}{1} & Regression & 1998.327 & 2 & 999.164 & 80.002 & $.000^{\mathrm{b}}$ \\
\hline & Residual & 1111.540 & 89 & 12.489 & & \\
\hline & Total & 3109.867 & 91 & & & \\
\hline \multicolumn{7}{|c|}{ a. Dependent Variable: KEPUTUSAN PENGAMBILAN KREDIT } \\
\hline \multicolumn{7}{|c|}{ b. Predictors: (Constant), PERSONAL SELLING, PROMOSI PENJUALAN } \\
\hline
\end{tabular}

Tabel 7 : Hasil Pengujian Secara Simultan (Uji F)

Sumber : Hasil Pengolahan SPSS 24

Diperoleh nilai Ftabel sebesar 80,002. Berdasarkan hasil perhitungan Fhitung sebesar 80,002 dengan nilai Ftabel sebesar 3,10 dan nilai signifikannya 0,000 . Karena dari hasil pengujian diperoleh nilai Fhitung $=80,002>$
Ftabel $=3,10$. Maka hasil pengujian dapat disimpulkan bahwa Promosi Penjualan dan Personal Selling berpengaruh secara signifikan terhadap Keputusan Pengambilan Kredit Tanpa Agunan. 
Tabel 8 : Hasil Pengujian Secara Parsial (Uji T)

\begin{tabular}{|c|c|c|c|c|c|c|}
\hline \multicolumn{7}{|c|}{ Coefficients $^{\mathbf{a}}$} \\
\hline & \multirow[b]{2}{*}{ Model } & \multicolumn{2}{|c|}{$\begin{array}{c}\text { Unstandardized } \\
\text { Coefficients }\end{array}$} & \multirow{2}{*}{\begin{tabular}{|c}
$\begin{array}{l}\text { Standardized } \\
\text { Coefficients }\end{array}$ \\
Beta \\
\end{tabular}} & \multirow[b]{2}{*}{$\mathrm{t}$} & \multirow[b]{2}{*}{ Sig. } \\
\hline & & B & Std. Error & & & \\
\hline \multirow[t]{3}{*}{1} & (Constant) & 4.259 & 1.991 & & 2.139 & .035 \\
\hline & PROMOSI PENJUALAN & .767 & .139 & .382 & 5.527 & .000 \\
\hline & PERSONAL SELLING & .339 & .041 & .568 & 8.218 & .000 \\
\hline
\end{tabular}

a. Dependent Variable: KEPUTUSAN PENGAMBILAN KREDIT

Sumber : Hasil Pengolahan SPSS 24

Dari tabel 8 Dapat diketahui hasil pengujian secara prsial antara variabel Promosi Penjualan dan Personal Selling terhadap Keputusan Pengambilan Kredit memperoleh nilaii thitung sebesar 5,527 dengan tingkat signifikan sebesar 0,000 dengan menggunakan batas signifikansi $<0,05$. Dari hasil tersebut dapat menunjukan bahwa thitung $(5,527>$ ttabel $(1,986)$ yang memiliki arti bahwa secara parsial Promosi Penjualan berpengaruh signifikan terhadap Keputusan Pengambilan Kredit. Hasil pengujian variabel Personal Selling memperoleh niali thitung sebesar 8,218 dengan tingkat signifikan sebesar 0,000 dengan menggunakan batas signifikansi

$<0,05$. Dari hasil tersebut dapat menunjukan bahwa thitung $(8,218>$ ttabel $(1,986)$ yang memiliki arti bahwa Promosi Penjualan berpengaruh signifikan terhadap Keputusan Pengambilan Kredit.

\section{Pembahasan}

\section{Pengaruh Promosi Penjualan terhadap}

\section{Keputusan Pengambilan Kredit}

Variabel Promosi Penjualan terhadap Keputusan Pengambilan Kredit menunjukkan bahwa Promosi Penjualan berpengaruh positif dan signifikan terhadap Keputusan Pengambilan Kredit di Bank CIMB Niaga Cabang Asia Afrika Bandung. Hal ini menunjukkan bahwa meningkatkan Keputusan Pengambilan Kredit memiliki keuntungan juga terhadap Promosi Penjualan yang dimiliki oleh perusahaan. Penelitian di atas juga diperkuat oleh penelitian yang dilakukan oleh Rananda Iman Cahya (2018) yang menunjukan bahwa promosi penjualan berpengaruh positif dan signifikan terhadap minat nasabah bertransaksi di bank syariah. Sehingga semakin kuat Promosi Penjualan yang dimiliki oleh perusahaan maka akan semakin meningkatkan minat nasabah bertran saksi di bank syariah.

\section{Personal Selling terhadap Keputusan}

\section{Pengambilan Kredit}

Variabel Personal Selling terhadap Keputusan Pengambilan Kredit menunjukkan bahwa Personal Selling berpengaruh positif dan signifikan terhadap Keputusan Pengambilan Kredit di Bank CIMB Niaga Cabang Asia Afrika Bandung. Hal ini menunjukkan bahwa meningkatkan Keputusan Pengambilan Kredit 
memiliki keuntungan juga terhadap Personal Selling yang dimiliki oleh perusahaan. Penelitian di atas juga diperkuat oleh penelitian yang dilakukan oleh Putri Nur Intan (2016) yang menunjukan bahwa Personal Selling berpengaruh positif dan signifikan terhadap keputusan nasabah dalam memilih pembiayaan mikro. Sehingga semakin kuat Personal Selling yang dimiliki oleh perusahaan maka akan semakin meningkatkan keputusan nasabah dalam memilih pembiayaan mikro.

\section{Pengaruh Promosi Penjualan dan Personal}

Selling terhadap Keputusan Pengambilan

\section{Kredit}

Secara parsial variabel independen berpengaruh secara positif terhadap variabel dependen. Sehingga memiliki arti semakin tinggi atau semakin baik variabel independen (Promosi Penjualan dan Personal Selling) maka semakin tinggi pula Keputusan Pengambilan

Kredit Tanpa Agunan di Bank CIMB Niaga Cabang Asia Afrika Bandung. Berdasarkan hasil uji secara parsial diperoleh nilai $\mathrm{f}_{\text {hitung }}$ lebih besar dari $\mathrm{f}_{\text {tabel }}(80,002>3,10)$ dimana Promosi Penjualan dan Personal Selling secara simultan berpengaruh terhadap Keputusan Pengambilan Kredit. Adapun pengaruh dari variabel promosi penjualan dan personal selling terhadap keputusan pengambilan kredit sebesar $80,002 \%$. Penelitian di atas juga diperkuat oleh penelitian yang dilakukan oleh Widya Marsa Hilda (2017) yang menunjukan bahwa Promosi
Penjualan dan Personal Selling berpengaruh positif dan signifikan terhadap keputusan nasabah menabung. Sehingga semakin kuat Promosi Penjualan dan Personal Selling yang dimiliki oleh perusahaan maka akan semakin meningkatkan keputusan nasabah menabung.

\section{KESIMPULAN}

Berdasarkan hasil penelitian dan pembahasan mengenai pengaruh Promosi Penjualan dan Personal Selling terhadap Keputusan Pengambilan Kredit di Bank CIMB Niaga Cabnag Asia Afrika Bandung, maka peneliti mengambil kesimpulan Variabel Promosi Penjualan (X1) dan Personal Selling (X2) berpengaruh positif terhadp keputusan pengambilan kredit, hal ini dibuktikan dengan Hasil pengujian variabel Promosi Penjualan memperoleh nilai thitung sebesar 5,527 dengan tingkat signifikan sebesar 0,000 dengan menggunakan batas signifikansi $<0,05$ dan Dari hasil tersebut dapat menunjukan bahwa thitung $(5,527>$ ttabel $(1,986)$ kemudian dari hasil pengujian variabel Personal Selling memperoleh nilai thitung sebesar 8,218 dengan tingkat signifikan sebesar 0,000 dengan menggunakan batas signifikansi

$<0,05$ dari hasil tersebut dapat menunjukan bahwa thitung $(8,218>$ ttabel $(1,986)$. Kemudian dari hasil pengujian secara simultan nilai $f_{\text {hitung }}$ lebih besar dari $f_{\text {tabel }}(80,002>3,10)$. Sehingga yang berkontribusi bersama - sama promosi penjualan dan personal selling terhadap keputusan pengambilan kredit sebesar 
$64 \%$ dan sisanya $36 \%$ dipengaruhi oleh faktor lain yang tidak diteliti. Maka disimpulkan bahwa secara simultan Promosi Penjualan dan Personal Selling berpengaruh positif dan signifikan terhadap Keputusan Pengambilan Kredit.

\section{SARAN}

Berdasarkan hasil penelitian menunjukkan bahwa ada pengaruh promosi penjualan dan personal selling terhadap keputusan pengambilan kredit. Selain itu hasil penelitian juga menunjukkan bahwa, promosi

penjualan, personal selling dan keputusan pengambilan kredit termasuk ke dalam kategori hubungan yang kuat. Adapun saran yang dapat peneliti sampaikan diantaranya upaya peningkatan promosi penjualan maka perusahaan sebaiknya menurunkan potongan biaya provisi pada saat pencairan dana. Jika seluruh dimensi dalam promosi penjualan dapat diaplikasikan dengan baik maka dapat merubah presepsi nasabah pada Bank CIMB Niaga hal ini akan meningkatkan promosi penjualan pada Bank CIMB Niaga. Untuk meningkatkan kinerja perusahaan dalam memenuhi harapan nasabah dalam personal selling dapat dilakukan dengan cara memperbaiki penampilan pakaian tenaga penjual agar terlihat lebih formal dan rapih. Jika seluruh dimensi dalam personal selling dapat diaplikasikan dengan baik maka dapat merubah presepsi nasabah pada Bank CIMB Niaga hal ini akan meningkatkan promosi penjualan pada Bank
CIMB Niaga. Sedangkan untuk meningkatkan tingkat keputusan pengambilan kredit pada nasabah dapat dilakukan dengan cara meningkatkan jumlah plafon pinjaman agar bisa sesuai dengan kebutuhan dan harapan nasabah. Jika seluruh dimensi dalam keputusan pengambilan kredit dapat diaplikasikan dengan baik maka dapat merubah presepsi nasabah pada Bank CIMB Niaga hal ini akan meningkatkan promosi penjualan pada Bank CIMB Niaga.

\section{DAFTAR PUSTAKA}

[1] Malau, H. (2017). Manajemen Pemasaran Teori dan Aplikasi Pemasaran Era Tradisional Sampai Era Moderenisasi Global. Bandung: CV. Alfabeta.

[2] Armstrong, P. K. (2016). Marketing In Introduction. USA: Perason Education.

[3] Donni Juni Priansa, S. M. (2017). Komunikasi Pemasaran Terpadu ( Pada Era Media Sosial ). Bandung: CV. Pustaka Setia.

[4] Yasa Cendriyansyah, A. M. (2017). Pengaruh Personal Selling Terhadap Keputusan Pembelian (Studi Kasus Pada Perum Perumnas Bumi Parahiyangan Kencana Soreang. e-Proceeding of Applied Science : Vol.3, No.2 Agustus 2017| Page 213, 3-4.

[5] Utami, D. R. (2018 - 2019).Pengaruh Suku Bunga Kredit, Kualitas Pelayanan, dan Prosedur Kredit Terhadap Keputusan Menjadi Nasabah Kredit Guna Bakti di Bank BJB Cabang Utama Bandung. Program Magister Manajemen Universitas Widyatama.

[6] Setyaningrum Ari, U. J. (2015). Prinsipprinsip Pemasaran. Yogyakarta: Andi. 
[7] Intan, P. N. (2016). Putri Nur Intan (2016) Pengaruh Personal Selling dan Perilaku Emosional terhadap Keputusan Nasabah Dalam Memilih Pembiayaan Mikro ( Studi Kasus pda PT Bank BRI Syariah Cabang Sidoarjo ). Universitas Islam Negeri Maulana Malik Ibrahim.

[8] Hilda, W. M. (2017). Widya Marsa Hilda (2017) Pengaruh Advertising, Sales
Promotion, Personal Selling, Direct Marketing Dan Corporate Image Terhadap Keputusan Nasabah Menabung Di Bank BRI Syariah Kantor Cabanf Pembantu Ungaran. PROGRAM STUDI S1 PERBANKAN SYARIAH FAKULTAS EKONOMI DAN BISNIS ISLAM INSTITUT AGAMA ISLAM NEGERI SALATIGA. 